\title{
Implementation of Strengthening State Science Knowledge Using Camp Study Methods on PPKn Students Of PGRI Banyuwangi University
}

\author{
Andika Ronggo Gumuruh¹, Agus Mursidi², Tofan Priananda Adinata ${ }^{3}$, Eko Listiwikono ${ }^{4}$ \\ ${ }^{1}$ Citizenship Education, Faculty Of Teaching And Education, PGRI Banyuwangi University \\ 23 History Education, Faculty Of Teaching And Education, PGRI Banyuwangi University \\ 4Mathematics Education, Faculty Of MIPA, PGRI Banyuwangi University \\ Email: agusmursidi78@gmail.com

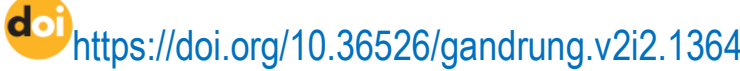

\begin{abstract}
Knowledge of state science is the basis for maintaining state institutions, so that research is carried out continuously and scientifically, as well as solving problems in students' knowledge of state science. The purpose of this service is to provide reinforcement to students about state science by presenting state science practitioners. Knowledge skills about state science and student attitudes towards the development of the country. This activity was attended by 25 PPkn students of PGRI Bnyuwangi University batch 2020. The method used was to present speakers of political practitioners and student activists in 1998 so that the level of student knowledge about state science and the role of students in the movement to build the nation could become the spirit of students in the reform era. In practice, students' knowledge of state science is increasing and it can be concluded that the role of students to maintain the institution is very important.
\end{abstract}

Keyword: State Science Knowledge, Camp Study Methods, PPKn Students

\section{Pendahuluan}

Salah satu tujuan terpenting dari pendidikan Kewarganegaraan adalah untuk mengajarkan mahasiswa bagaimana terlibat dalam pembangunan negara. Dengan kata lain, mahasiaswa harus mengintegrasikan keterampilan, pengetahuan, dan sikap untuk mengembangkan pemahaman konsep ilmiah yang lebih baik. Jadi Dosen harus fokus pada pengajaran keterampilan sains seperti fakta, konsep dan teori, untuk mendorong siswa melalui penyelidikan ilmiah. Pengetahuan tentang ilmu negara adalah sebagai dasar untuk menjaga insitusi Negara, maka dilakukan penguatan dan penelitian ilmiah, dan memecahkan masalah dalam pengetahuan mahasiswa tentang ilmu Negara (Aktamis, 2008). Colvill dan Pattie (Colvill, 2002) mendalilkan bahwa kegiatan yang terdiri dari keterampilan penguatan ilmu Negara terpadu terpadu merupakan faktor kunci literasi dan dimensi kunci literasi sains/sains (Bayu Indra Permana, 2021). Implementasi penguatan ilmu negara dikenal sebagai IImu prosedural, eksperimen dan kebiasaan yang wajib di ketahui oleh mahasiswa Pendidikan Pancasila dan Kewarga negaraan.

Penguatan ilmu negara pada umumnya dilakukan dalami suatu proses belajar, ini terjadi karena seperti sifat manusia yang tidak akan pernah puas pada sesuatu yang belum diketahuinya. Sosialisasi 
GANDRUNG: Jurnal Pengabdian Kepada Masyarakat ISSN: 2721-6136 (Online)

tersebut bentuk upaya memberikan penjelasan pada suatu objek yang akan diterima kepada subjek. Sosialisasi biasa dilakukan dalam suatu agenda perkumpulan baik formal atau non formal, sehingga sosialisasi dianggap sangat penting agar tujuan dapat tercapai. Menurut Berns sosialisasi adalah proses yang di dalamnya manusia sejak lahir memperoleh keterampilan-keterampilan untuk berfungsi sebagai makhluk sosial dan partisipan dalam masyarakat. Manusia dapat bersosialisasi dalam kehidupan masyarakat yang berpedoman pada norma-norma.

Sosialisasi sebagai proses belajar seorang individu merupakan salah satu faktor yang mempengaruhi bagaimana keberlangsungan proses kehidupan masyarakat, baik dengan keluarga, teman sebaya, sekolah maupun media massa (Harwanti Noviandari, 2016). Unsur-unsur pengertian sosialisasi adalah sosialisasi merupakan cara belajar atau suatu proses akomodasi dan yang dipelajari adalah nilainilai, norma-norma, ide-ide atau gagasan, pola-pola tingkah laku dan adat istiadat serta keseluruhannya itu diwujudkan dalam kepribadiannya. Keseluruhannya itu merupakan segala aspek dari proses kehidupan manusia yang berhubungan erat dengan sosialisasi menyangkut keberhasilan ataupun kegagalan sosialisasi.

Sosialisasi juga sebagai proses belajar individu dalam kehidupan bermasyarakat, kehidupan yang berpedoman pada norma-norma. Norma merupakan kaidah, pokok, kadar atau patokan yang diterima secara utuh oleh masyarakat guna mengatur kehidupan dan tingkah laku sehari-hari, agar hidup ini terasa aman dan menyenangkan. Norma sendiri masih terbagi menjadi beberapa jenis seperti norma agama, norma kesusilaan, norma hukum dan adat istiadat, sifatnya pun bermacam-macam seperti ringan lunak, memperbolehkan dan menggunakan sedikit paksaan dan bisa sebaliknya bersifat melarang sama sekali bahkan menjadi tabu. Artinya dilarang menjamin atau melakukannya karena diliputi kekuatankekuatan gaib yang lebih tinggi. Norma bisa juga berupa larangan-larangan dengan sanksi keras, hukuman atau tindak pengasingan.

\section{Metode}

Strategi pengabdian ini adalah menggunakan metode ceramah dalam acara seminar dan pelatihan dengan menghadirkan narasumber utama yaitu dari praktisi aktifis mahasiswa 1998 dan dosen ilmu social serta dosen ilmu Negara dalam konsep study camp yang melibatkan 25 mahasiswa pendidikan pancasila dan Kewarganegaraan dengan di damping 4 orang dosen Fakultas Keguruan dan IImu Pendidikan universitas PGRI Banyuwangi. Kegitan ini dilaksanakan selama tiga hari pada tanggal 26 - 28 Juni 2021 bertempat di wisata sumber waras desa Taman Suruh kecamatan Glagah Kabupaten Banyuwangi dengan lama kegitan secara keseluruhan tiga bulan mulai dari perencanaan dan 
GANDRUNG: Jurnal Pengabdian Kepada Masyarakat ISSN: 2721-6136 (Online)

pelaksanaan dan laporan kegitan serta publikasi ilmiah

\section{Hasil dan Diskusi}

1. Kurikulum 2021 dengan kosep Merdeka Belajar oleh Dr. Agus Mursidi, M.Pd

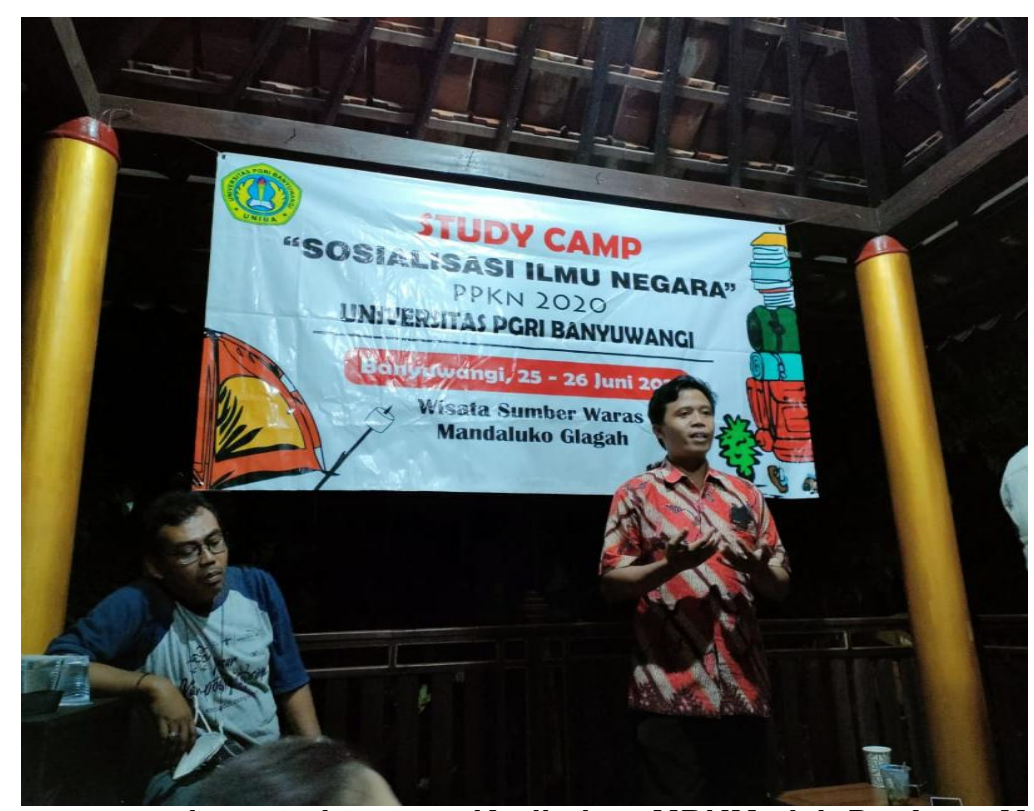

Gambar 1. penyampain materi tentang Kurikulum MBKM oleh Dr. Agus Mursidi, M.Pd

Menteri Pendidikan dan Kebudayaan, Nadiem Makarim menyebutkan sejumlah kegiatan belajar mahasiswa Sarjana Satu (S-1) di luar kampus akan mendapatkan bobot penilaian Sistem Kredit Semester (SKS). Hal itu merupakan bagian dari kebijakan Kampus Merdeka yakni hak belajar tiga semester di luar program studi dan di luar kampus (Widiyono, 2021). Adapun kegiatan-kegiatan yang bakal masuk penilaian SKS adalah magang atau praktik kerja di industri atau organisasi, pertukaran pelajar, pengabdian masyarakat, wirausaha, riset, studi independen, maupun kegiatan mengajar di daerah terpencil, dan kegiatan lainnya yang disepakati dengan program studi (Yusuf, 2021). Perguruan tinggi wajib memberikan hak bagi mahasiswa untuk secara sukarela, jadi mahasiswa boleh mengambil ataupun tidak SKS di luar kampusnya sebanyak dua semester atau setara dengan 40 sks, ucap Nadiem mengatakan setiap kegiatan yang dipilih mahasiswa harus dibimbing oleh seorang dosen yang ditentukan kampusnya (Tinggi, 2020).

Dalam kegiatan Study Camp Imu Negara PPKn 2020 yang dilaksanakan pada tanggal 25-26 Juni 2021 tersebut memberikan banyak sekali wawasan mengenai pemerintahan dan juga negara,dalam kegiatan tersebut bisa dijadikan suatu pembelajaran tentang bagaimana bentuk 
GANDRUNG: Jurnal Pengabdian Kepada Masyarakat ISSN: 2721-6136 (Online)

negara,pemerintahannya,bagaimana sebuah politik bisa berjalan di negara tersebut,dan dari materi yang sampaikan yang terpenting adalah kita bisa mengetahui tata cara pembuatan rancangan undangundang dan bagaimana supaya undang-undang tersebut dapat disetujui atau tidak atas kehendak masyarakat atau rakyat,karena pada dasarnya di Indonesia menganut system demokrasi dimana di butuhkan musyawarah untuk mencapai segala keputusan dan tindakan karena kekuasaan tertinggi adalah berada ditangan rakyat.

Kegiatan Study Camp IImu Negara PPKn 2020 tersebut juga menjadi sarana bagi mahasiswa untuk menumbuhkan rasa kekeluargaan antar sesama teman dan masyarakat melalui musyawarah yang demokrasi. Dari sinilah mahasiswa dapat belajar banyak dalam hal-hal tertentu khususnya mengenai negara,selain musyawarah demokrasi dalam kegiatan ini juga dapat membentuk sikap disiplin dalam pengamalan Pancasila sebagai landasan idiil bangsa Indonesia,dimana mengajarkan kita untuk disiplin, gotong royong,bela negara dan lainnya.

2. IImu Negara oleh Andika Ronggo Gumuruh

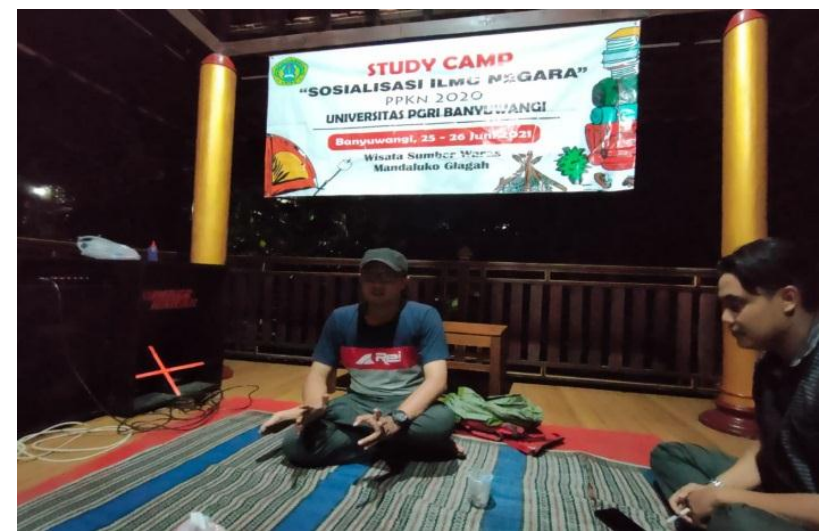

Gambar 2. Penyampaian materi tentang Ilmu Negara oleh Andika Ronggo G. M.H

Demokrasi tidak lah mudah untuk dilaksanakan bahkan tidak semakin mudah. Demokrasi dalam melibakan banyak orang, namun secara lebih intensif untuk lebih mengutamakan diri mereka sendiri tumbuh semakin kuat setiap tahun karena mengalami degredasi demokraasi dan hubungan sosial di antara budaya-budaya dunia yang sangat mementingkan diri sendiri. Banyak dari hubungan itu yang di pengaruhi oleh teknologi, sehingga peran mahasiswa dalam melihat sistem teknologi sebagai situs dan objek penting dari tata kelola pelaksanaan demokrasi (Hackett, 2007) (Jasanoff, 2006). Pada saat yang sama, informasi yang dibutuhkan untuk membuat kebijakan yang berkembang dalam suatu negara, menciptakan tranformasi informasi tentang perkembangan lembaga negara, baik berupa material, dan social budaya. Bagaimana demokrasi dapat dipertahankan dalam arti yang berarti dalam masyarakat 
yang diresapi teknologi, di mana pengetahuan terspesialisasi, nilai-nilai bertentangan, produsen seringkali jauh dari konsumen dan pengguna akhir, dan kurangnya bahasa dan norma yang sama membuat fantasi tentang ruang publik klasik yang dihuni olehJu"rgen Habermas (1984"komunitas pidato ideal")? Bagaimana, lebih khusus lagi, lintasan inovasi teknologi dapat diarahkan untuk mengambil alih pemahaman yang meningkat tentang sistem yang kompleks, yang seringkali berasal dari bidang interdisipliner seperti mahasaiswa, dan kebutuhan serta preferensi orang banyak secara global? Ini adalah beberapa dilema yang dibahas dalam pertemuan akademis.

Konsep tersebut, dalam pandangannya, bersifat evaluatif (yaitu, mereka menyampaikan penilaian sarat nilai tentang elemen yang kita inginkan, atau tidak ingin, untuk membangun ke dalam tatanan sosial) dan secara internal kompleks (yaitu, definisi mereka menggabungkan beberapa, konstitutif tidak dapat direduksi elemen). Ketidaksepakatan muncul dan bertahan atas makna konsep-konsep tersebut karena orang mungkin memberi peringkat, menimbang, dan menafsirkan elemen-elemen ini dengan sangat berbeda. Apa yang menurut seorang pengamat sebagai demokrasi sempurna mungkin tampak tidak memadai bagi pengamat lain dalam hal-hal yang menonjol, meskipun keduanya sepakat bahwa sesuatu yang disebut demokrasi itu ada, bahwa ada prinsip-prinsip inti tertentu yang mendefinisikannya, dan bahwa sangat bermanfaat untuk memasukkan prinsip-prinsip ini ke dalam praktik politik. Kontestasi berpusat pada apakah cara-cara tertentu dalam mengatur politik menawarkan versi demokrasi yang cukup baik; musuh mungkin tidak pernah mencapai konsensus karena mereka tidak setuju pada tingkat meta tentang bagaimana menimbang berbagai faktor yang relevansinya, tetapi tidak yang relatif penting, disepakati oleh semua pihak. Ideologi penting dalam kontes semacam itu. Dengan demikian, penggemar pasar bebas yang keras mungkin memandang praktik kolektivisasi negara kesejahteraan sebagai terlalu mengganggu, sedangkan seorang sosialis yang berkomitmen mungkin keberatan dengan ketidakadilan distributif yang dihasilkan dari inovasi yang tidak memperhatikan norma-norma kolektif yang penting, seperti kelestarian lingkungan, keamanan nasional, akses terbuka atau pengentasan kemiskinan. 
GANDRUNG: Jurnal Pengabdian Kepada Masyarakat ISSN: 2721-6136 (Online)

3. Peran mahasaiswa di era reformasi Hari pranoto

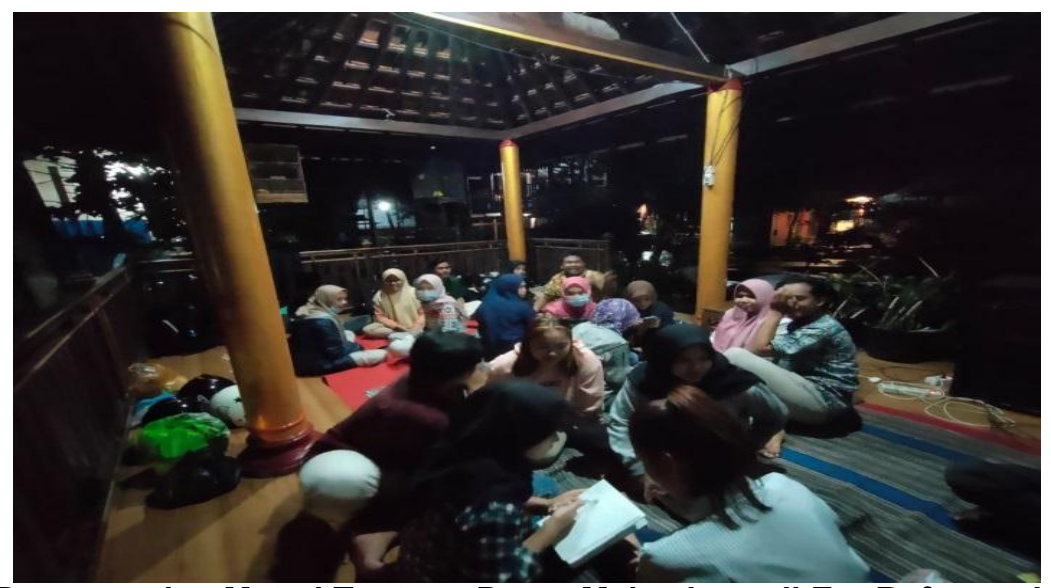

Gambar 3. Penyampaian Materi Tentang Peran Mahasiswa di Era Reformasi oleh Hari

Pranoto,M.T.

Mahasiswa selalu menjadi bagian dari perjalanan sejarah dari sebuah bangsa. Roda sejarah demokrasi selalu menyertakan mahasiswa sebagai pelopor, penggerak, bahkan sebagai pengambil keputusan. Hal tersebut telah terjadi di berbagai negara di dunia, baik di Timur maupun di Barat. Contoh mulai dari masa presiden soekarno - soeharto mahasiswa mengambil peran dalam perubahan kebijakan bangsa. Pemikiran kritis, demokratis, dan konstruktif selalu lahir dari pola pikir para mahasiswa. Suarasuara mahasiswa kerap kali merepresentasikan dan mengangkat realita sosial yang terjadi di masyarakat. Sikap idealisme mendorong mahasiswa untuk memperjuangkan sebuah aspirasi pada penguasa, dengan cara mereka sendiri.

Dalam hal ini, secara umum mahasiswa menyandang tiga fungsi strategis, yaitu :

1. Sebagai penyampai kebenaran (agent of social control)

2. Sebagai agen perubahan (agent of change)

3. Sebagai generasi penerus masa depan (iron stock)

Mahasiswa dituntut untuk berperan lebih, tidak hanya bertanggung jawab sebagai kaum akademis, tetapi diluar itu wajib memikirkan dan mengembang tujuan bangsa. Dalam hal ini keterpaduan nilai-nilai moralitas dan intelektualitas sangat diperlukan demi berjalannya peran mahasiswa dalam dunia kampusnya untuk dapat menciptakan sebuah kondisi kehidupan kampus yang harmonis serta juga kehidupan diluar kampus.

Peran dan fungsi mahasiswa dapat ditunjukkan dengan cara memiliki prilaku secara santun tanpa mengurangi esensi dan agenda yang diperjuangkan. Semangat mengawal dan mengawasi jalannya reformasi, harus tetap tertanam dalam jiwa setiap mahasiswa. Sikap kritis harus tetap ada dalam diri 
mahasiswa, sebagai agen pengendali untuk mencegah berbagai penyelewengan yang terjadi terhadap perubahan yang telah mereka perjuangkan. Dengan begitu, mahasiswa tetap menebarkan bau harum keadilan sosial dan solidaritas kerakyatan.

Sebagai kelompok masyarakat yang memperoleh pendidikan terbaik, mahasiswa mempunyai horison yang luas diantara masyarakat. Sebagai kelompok masyarakat yang paling lama menduduki bangku sekolah, sampai di universitas mahasiswa telah mengalami proses sosialisasi politik yang terpanjang diantara angkatan muda. Kehidupan kampus membentuk gaya hidup yang unik di kalangan mahasiswa. Di Universitas, mahasiswa yang berasal dari berbagai daerah, suku, bahasa dan agama terjalin dalam kegiatan kampus sehari-hari.

Mahasiswa sebagai kelompok yang akan memasuki lapisan atas dari susunan kekuasaan, struktur perekonomian dan prestise dalam masyarakat dengan sendirinya merupakan elit di dalam kalangan angkatan muda. Pada saat generasi yang memmipin bangsa ini sudah mulai berguguran pada saat itulah kita yang akan melanjutkan tongkat estafet perjuangan bangsa ini. Namun apabila hari ini ternyata kita tidak berusaha mambangun diri kita sendiri apakah mungkin kita kan membangun bangsa ini suatu saat nanti? Jawabannya ada pada diri anda masing-masing (Firdaus, 2015).

Kemampuan yang harus dimiliki seorang mahasiswa diera reformasi sangatlah berat untuk bersaiang di dunia industri dan pemerintahan sehingga diperlukan kemampuan-kemampuan yang harus di kuasai seperti:

1. Soft skill (Kemampuan Kepribadian)

Soft Skill atau kemampuan kepribadian adalah salah satu faktor untuk sukses pada pendidikan yang ditempuh dan juga penentu untuk masa depan seseorang dalam menjalani hidupnya. Karena soft skill hampir $80 \%$ menentukan keberhasilan seseorang.Kemampuan soft skill yang perlu dimiliki seorang mahasiswa, Manajemen waktu, Kepemimpinan (leadership), Tingkat kepercayaan yang tinggi (self confidence),Selera humor yang tinggi (sense of humor), Memiliki keyakinan dalam agama (spiritual capital)

\section{Hard Skill (Kemampuan Intelektual)}

Kemampuan intelektual hanya mendukung $40 \%$ darikonsep Merdeka Belajardari pencapaian prestasi dan keberhasilan seseorangJika kemampuan soft skill ini kita punyai, maka kita akan menjadi orang yang baik di masa depan, sebab saat ini yang terjadi banyak orang yang penting tapi sedikit yang baik 
GANDRUNG: Jurnal Pengabdian Kepada Masyarakat ISSN: 2721-6136 (Online)

\section{Kesimpulan}

Mahasaiswa Pendidikan Pancasila dan Kewarganegaraan harus paham betul dalam tataran ilmu Negara dan mampu memberikan masukan kepada pemerintah tentang desain prosedur untuk keterlibatan publik. Setiap fungsi instrumental tersebut harus dilakukan secara konsisten dengan kewajiban interpretatif dan normatif akademik sebagai disiplin ilmu sosial. Sehingga dapat di simpulakn pertama memperluas cakupan tindakan negara serta partisipasi publik, dengan aturan akses yang diliberalisasi dan tinjauan yudisial yang simpatik; yang kedua mengurangi peran negara, mendorong munculnya kompleks akademik untuk transfer teknologi, dan memprivatisasi debat nilai melalui peningkatan delegasi kepada ahli etika profesional. Sehingga mahasiswa yang Pemikiran kritis, demokratis, dan konstruktif sebagai penjaga konstitusi.

\section{Daftar Referensi}

Aktamis, H. \&. (2008). The effect of scientific process skills education on students scientific creativity. Paper presented at Asia-Pacific Forum on Science Learning and teaching. Asia-Pacific: science attitudes and academic achievements.

Bayu Indra Permana, A. M. (2021). Perception Fishermen Community about the Importance of 12 Years of Formal Education. International Journal for Educational and Vocational Studies, Vol. 2 Issu. 1.

Colvill, M. \&. (2002). The building blocks for scientific literacy. I. Australian Primary \& Junior Science Journa, 18(3), 20-30. .

Firdaus, K. M. ( 2015). Developing Critical Thinking Skills of Students in Mathematics Learning. Journal of Education and Learning, Vol. 9(3) pp. 226-236.

Hackett, E. J. (2007). eds. Handbook of science and technolog y studies, 3rd edn. Cambridge: MA: MIT Press.

Harwanti Noviandari, J. K. (2016). Teknik Cognitive Restructuring Untuk Meningkatkan Self Efficacy Belajar Siswa. Jurnal psikologi: Jurnal ilmiah fakultas psikologi universitas yudharta pasuruan, Vol.3 No.2 PP 76-86.

Jasanoff, S. (2006). Technology as a site and object of politics. In C. Tilly \& R. Goodin (Eds.): Oxford.

Tinggi, D. J. (2020). Buku Panduan Merdeka Belajar-Kampus Merdeka. Jakarta: Direktorat Jenderal Pendidikan Tinggi Kementerian Pendidikan Dan Kebudayaan.

Widiyono, A. I. (2021). Implementasi Merdeka Belajar Melalui Kampus Mengajar Perintis Di Sekolah Dasar. Metodik Didaktik. Jurnal Pendidikan Ke-Sd-An, 16(2).

Yusuf, M. \&. (2021). Konsep "Merdeka Belajar" dalam Pandangan Filsafat Konstruktivisme. AL- 
GANDRUNG: Jurnal Pengabdian Kepada Masyarakat ISSN: 2721-6136 (Online)

MURABBI. Jurnal Studi Kependidikan Dan Keislaman, 7(2), 120-133. 